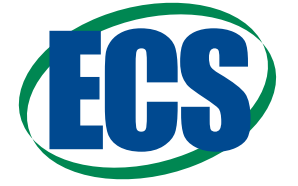

\title{
Thermally Driven SOFC Degradation in 4D: Part I. Microscale
}

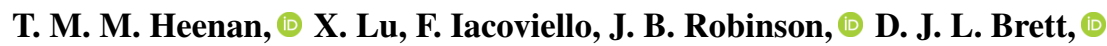 \\ and P. R. Shearing $\oplus^{\mathrm{Z}}$
}

Electrochemical Innovation Lab, Department of Chemical Engineering, UCL, London WC1E 7JE, United Kingdom

Solid oxide fuel cells (SOFCs) still suffer from many performance and lifetime issues due to complex degradation mechanisms such as sintering and delamination, particularly when exposed to high thermal ramp rates. This work presents the first of a twopart study investigating such degradation with a focus on the microscale. It is found that, compared to long-duration operation, nickel sintering during start-up and shut-down is minor even at low ramp-rates $\left(3^{\circ} \mathrm{C} \cdot \mathrm{min}^{-1}\right)$. Moreover, thermal ramp-rates during heating have a negligible influence on the extent of particle-particle delamination during operational cycling; a similar magnitude of $\mathrm{Ni}$-YSZ interfacial particle contact loss is observed after each thermal cycle for ramp rates from $3-30^{\circ} \mathrm{C} \cdot \mathrm{min}^{-1}$. Tortuosity-factor and percolation values remain consistent after the first thermal cycle, where Ni mobility may homogenize the structure during low ramp-rates. Both sintering and delamination are correlated to the triple-phase boundary (TPB) losses but for operational thermal cycling with minor dwell times, the particle-particle delamination is the prominent mechanism. This two-part study is the first report of an extended 4D analysis into the effects of thermal cycling on the anode structure with sub-micron resolution using only lab-based instruments. These findings will lead to improved cell designs, ultimately extending device lifetimes.

(C) The Author(s) 2018. Published by ECS. This is an open access article distributed under the terms of the Creative Commons Attribution 4.0 License (CC BY, http://creativecommons.org/licenses/by/4.0/), which permits unrestricted reuse of the work in any medium, provided the original work is properly cited. [DOI: $10.1149 / 2.0151811 \mathrm{jes}]$

(cc) BY

Manuscript submitted May 14, 2018; revised manuscript received July 19, 2018. Published August 11, 2018.

SOFCs can provide energy for a large range of applications although cost and durability issues continue to obstruct entry to the mass-market. Moreover, in order to compete with existing technologies, many applications require rapid operational start-up and shutdown times which often necessitates high thermal ramp-rates, accelerating degradation. Therefore great effort has been applied in the pursuit of improved understanding of the processes responsible for losses in cell performance during operational cycling. High-temperature fuel cells such as the solid oxide fuel cell (SOFC) allow fast reaction kinetics, fuel versatility and high net efficiencies without the need for expensive catalysts. ${ }^{1}$ However, an inability to withstand thermal cycling due to the mismatch in the thermal expansion coefficients (TECs) of the constituent materials remains a prominent source of cell degradation. ${ }^{2-4}$

The reaction sites within the electrodes are named the triple-phase boundaries (TPBs), due to the three transport networks which are essential in the production of current from an SOFC: the transport of electrons through the metal, oxide ions $\left(\mathrm{O}^{2-}\right)$ through the ceramic and gaseous reactants/products through the pores. The location where these three networks meet is where the TPB is located and is characterized by a one-dimensional reaction site length $\left(\mathrm{L}_{\mathrm{TPB}}\right)$. In order to compare the population of TPBs between different electrodes the TPB density $\left(\rho_{T P B}\right)$, the $\mathrm{L}_{\text {TPB }}$ per unit volume, has become a common metric in the assessment of electrode performance. ${ }^{5}$

Recent advancements in characterization techniques have produced several methods for the quantification of the $\rho_{T P B}$. The use of focused-ion beams (FIB) in combination with scanning electron microscopes (FIB-SEM), allowed the creation of 3D images although as this requires the destruction of the sample through the FIB milling to expose each SEM slice, this eliminated the possibility of repeated analysis within the same region of interest (ROI). ${ }^{6}$ Methods then moved to the use of specialist synchrotron facilities using high-brilliance X-ray beams to produce $3 \mathrm{D}$ reconstructions using computed tomography (CT) without the destruction of the sample. ${ }^{7-10}$ The non-destructive nature of X-ray CT allowed the development of 4D studies (3 spatial dimensions plus time).$^{3,11-13}$ However, access to such facilities can be limited, restricting the number of long-duration investigations. Recent developments in lab-based techniques have produced a host of X-ray CT instruments capable of imaging across multiple lengthscales without the destruction of the sample or the need to access synchrotron facilities. ${ }^{14-16}$

SOFC anode performance is known to reduce through several degradation mechanisms during operational cycling as summarized

${ }^{\mathrm{z}}$ E-mail: p.shearing@ucl.ac.uk by Yokokawa et al. ${ }^{17}$ Recent studies by Song et al. have suggested that the volume changes associated with anode oxidation cycling may result in the delamination and detachment of the metal from the ceramic. ${ }^{18}$ A similar mechanism is thought to occur during thermal cycling due to the TEC mismatch between the metal and ceramic, as investigated through complex 3D models by Clague et al. ${ }^{19}$ and Celik et al. ${ }^{20}$ Although the addition of YSZ to the anode is thought to reduce macroscopic expansion mismatch during thermal cycling, diffraction techniques have found expansion-induced stress to remain problematic, often producing complex, non-linear strain..$^{21,22}$ The addition of a YSZ skeleton to the anode is also thought to inhibit the sintering of the $\mathrm{Ni}$ metal, however, sintering remains a significant source of impedance during long-duration operation. ${ }^{11,23,24}$ TEC mismatch and sintering are prominent sources of anode degradation; however, literature describing such mechanisms during operational thermal cycling remains limited ${ }^{3,25,26}$ and requires further study.

This work presents the first extended study of the microstructure evolution of a Ni-YSZ anode within the same ROI throughout operational thermal cycling. By quantifying the properties which contribute to cell performance, the microstructural evolution has been mapped and tracked in 3D, decoupling the mechanisms responsible for reaction site losses. Studies such as this will advance our understanding of degradation mechanisms, improving cell performance and ultimately extending device lifetimes.

\section{Experimental}

Materials and sample preparation.-In order to collect 3D structural information from an SOFC interface during thermal cycling a sufficiently small sample was required; an $800 \mu \mathrm{m}$ diameter pillar was therefore removed from a planar, anode supported anode/electrolyte solid oxide half-cell (Fuel Cell Materials, OH, USA) using a laser micro-machining technique (A Series/Compact Class 4 $532 \mathrm{~nm}$ Laser Micromachining System, Oxford Lasers, Oxford, UK) as described elsewhere. ${ }^{27}$ The cell consisted of a $500 \mu \mathrm{m}$ nickel oxide (NiO) - 8mol\% yttria stabilized zirconia (8YSZ) cermet (NiO-8YSZ) anode and a $10 \mu \mathrm{m} 8 \mathrm{YSZ}$ ceramic electrolyte, as specified by the manufacturer. Once removed from the bulk, the $800 \mu \mathrm{m}$ pillar was attached to an alumina tube using high-temperature cement ${ }^{16}$ before being milled further to ca. $350 \mu \mathrm{m}$ in diameter.

Lab-based X-ray micro-CT.-All structural information was obtained under the same imaging conditions using a lab-based $\mathrm{X}$ ray micro-CT instrument (Zeiss Xradia 520 Versa, Carl Zeiss., CA, USA). Five tomograms are presented in this work and for each, 2401 
a)

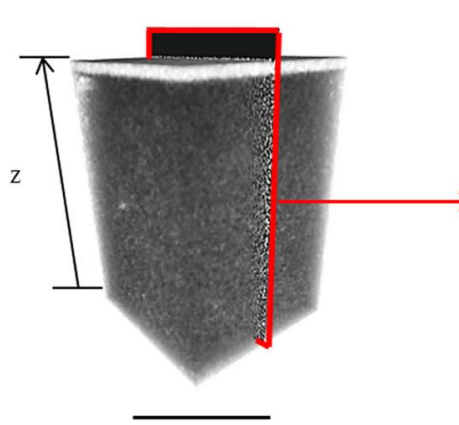

$100 \mu \mathrm{m}$ b)

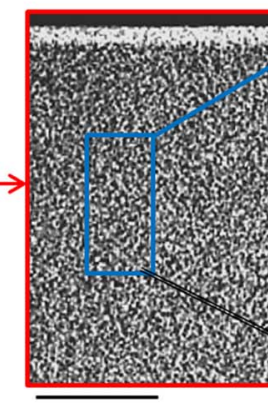

$50 \mu \mathrm{m}$ c)

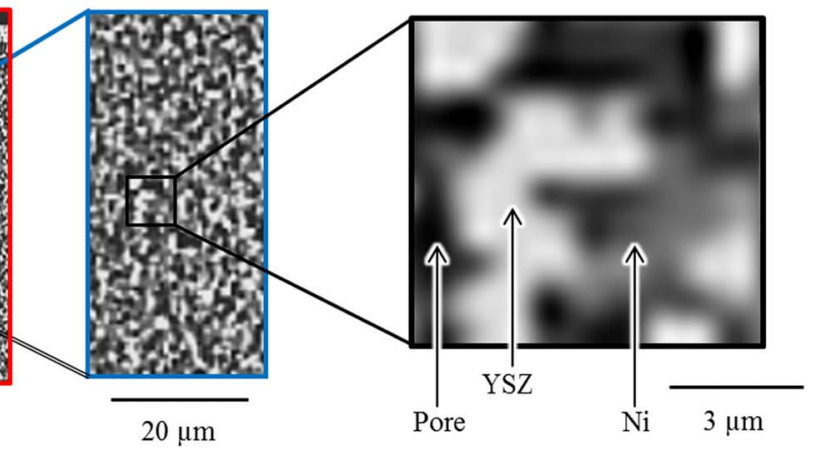

e)

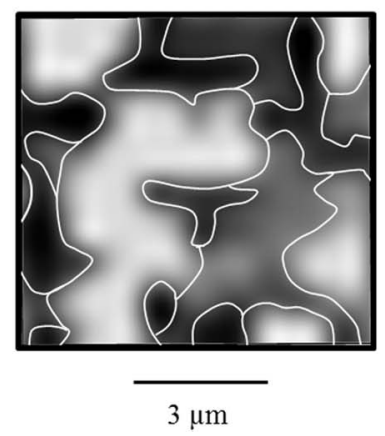

f)

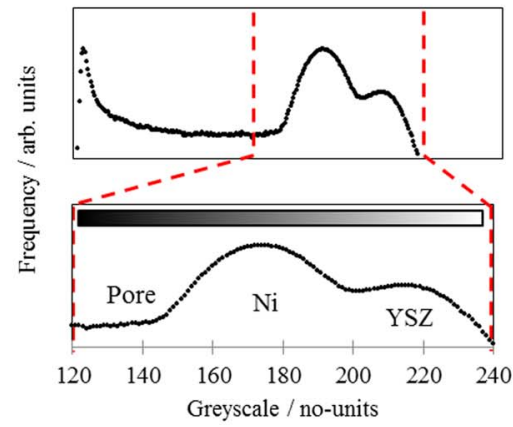

g)

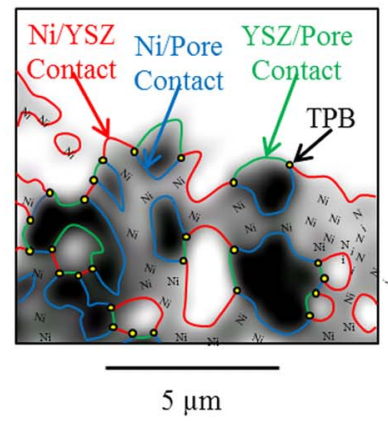

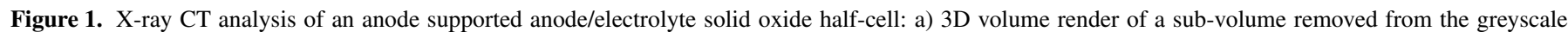

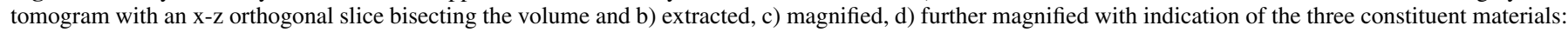

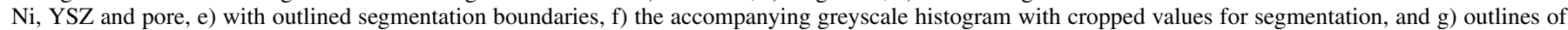
phase boundaries and TPB locations on an interfacial sub-slice.

radiograph projections were collected at an exposure of $30 \mathrm{~s}$ each achieving an isotropic pixel length of $395 \mathrm{~nm}$ (binning 2) with a square field of view (FOV) of $384 \mu \mathrm{m} \times 384 \mu \mathrm{m}$. The radiographs were reconstructed using commercial software ('XMReconstructor Scout-and-Scan', Zeiss, Carl Zeiss., CA, U.S.A.) using cone-beam filtered back projection algorithms, resulting in a sample volume of approx. $2 \times 10^{7} \mu \mathrm{m}^{3}$.

Thermal cycling.-All thermal treatments were conducted in an electrically heated, quartz tubular furnace with an internal forming gas atmosphere $\left(4 \% \mathrm{H}_{2} 96 \% \mathrm{~N}_{2}\right)$. Prior to the collection of any structural information the metal within the fuel cell anode was first reduced from nickel oxide $(\mathrm{NiO})$ to nickel $(\mathrm{Ni})$, producing a Ni-8YSZ cement. Reduction was conducted using a $3^{\circ} \mathrm{C} \cdot \mathrm{min}^{-1}$ thermal ramp rate to $800^{\circ} \mathrm{C}$ where the sample was held isothermally for 2 hours before being allowed to cool passively. Once reduced to Ni-YSZ the sample was imaged using the $\mathrm{X}$-ray CT instrument and then reinserted into the tubular furnace to be thermally cycled to mimic an operational startup and shut-down. Operational thermal cycling was conducted from room temperature to $750{ }^{\circ} \mathrm{C}$, according to manufacturing guidelines. ${ }^{28}$ This was conducted four times with the thermal ramp-rate increased for each cycle: $3,10,20$ and $30^{\circ} \mathrm{C} \cdot \mathrm{min}^{-1}$ for the second, third, fourth and fifth cycles respectively. In total five thermal cycles were accumulated with five tomograms collected, one after each thermal cycle: the reduction cycle plus the four operational thermal cycles. All tomograms were collected at room temperature.

Computation.-Four computational packages were used for the quantitative analysis within this study: Avizo Fire (Avizo, Thermo Fisher Scientific, Waltham, Massachusetts, U.S.), a MATLAB algorithm (Mathworks, Natick, Massachusetts, U. S. A.) as discussed by
Lu et al., ${ }^{29}$ an open-source MATLAB application TauFactor, as described by Cooper et al. ${ }^{30}$ and, ImageJ (ImageJ, National Institute of Health, U.S.A) as described by Schneider et al. ${ }^{31}$ All 3D images were created using Avizo visualizations via surface generations and volume renders. 3D data was also aligned using Avizo software to ensure the same region of interest was inspected for each dataset.

Three-phase segmentation.-Before analysis of the microstructural data could be initiated, segmentation of the three anode phases: metal (Ni), ceramic (YSZ) and pore, was required for each dataset, this was accomplished with the use of Avizo Fire. To verify the greyscale phase identification and ensure the consistency of the phase segmentations between different datasets, the authors employed the use of known materials within the X-ray FOV as greyscale-fiducials from which reference points within each tomogram's histogram could be established, and used as a basis for the segmentation of the rest of the anode. The first greyscale-fiducial was the electrolyte: known to be at the top of the sample and ca. $10 \mu \mathrm{m}$ in thickness (Figures 1a and 1b), a large volume of bright greyscale values from the electrolyte bulk were referenced to the whole tomogram's histogram. A large volume of dark greyscale values from the open pore above the electrolyte was used as the second greyscale-fiducial; again, these greyscale values were referenced to the tomogram's histogram (Figure 1). Using these two references, the voxels which were considered to represent ceramic and pore materials were removed from the $3 \mathrm{D}$ volume and the remaining voxels were considered to be occupied entirely by $\mathrm{Ni}$. After segmentation there existed fifteen datasets: a 3D dataset of each of the three phases for each of the five thermal cycles.

Spatial orientation.-The orthogonal planes $(x, y, z)$ could be used to identify the orientation of the sample with respect to its position 
a)

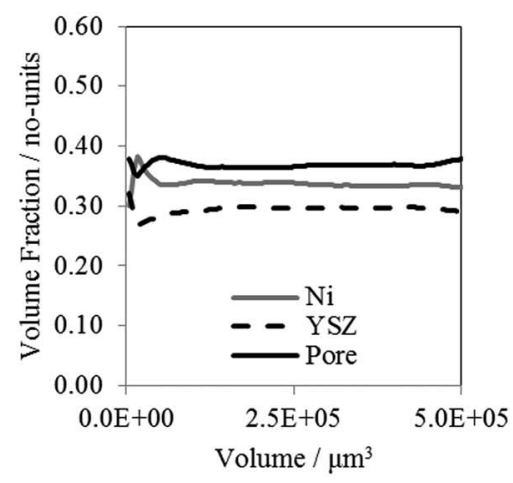

b)

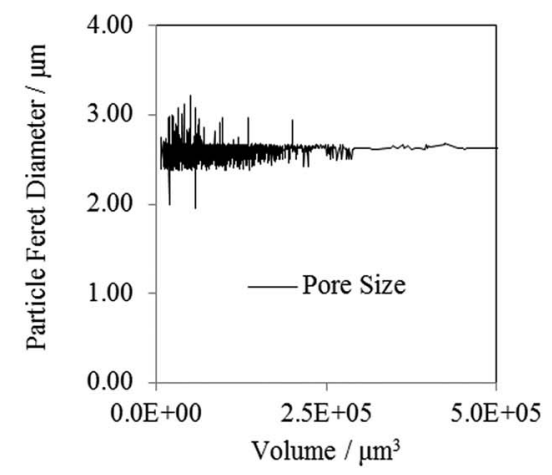

c)

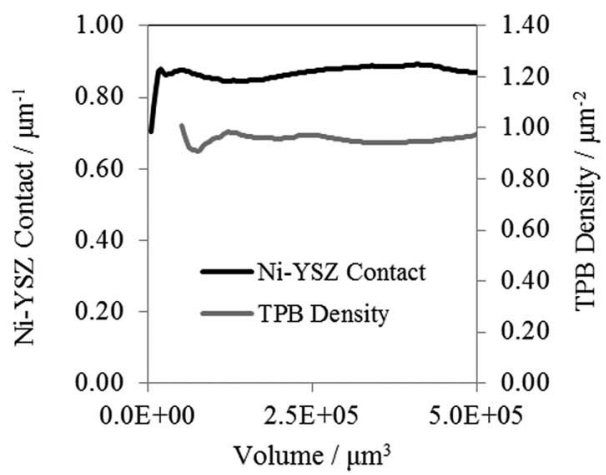

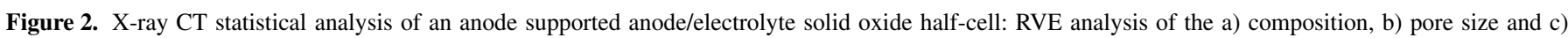
Ni-YSZ contact area and TPB density.

within an operating stack, i.e. the orientation of the fuel and air inlets. This was possible because, unlike imaging purely anode materials, ${ }^{15}$ an electrolyte layer sat within the FOV of the X-ray CT, and therefore the spatial orientation of the microstructure with respect to the stack geometry could be extracted from the anode: throughout, the z-plane is defined as the axes perpendicular to the anode/electrolyte interface, whereas the $\mathrm{x}$ - and $\mathrm{y}$-planes are defined as both parallel to the interface and perpendicular to one another.

Notation.-Variables which are phase-specific are denoted $\mathbf{v}_{j}$ where $j=N i, Y S Z$ or pore, directional variables are denoted $\mathrm{v}_{i}$ where $i=x, y$ or $z$, and, variables which involve two phases are denotes, $\mathrm{v}_{\mathrm{j}, \mathrm{k}}$ where $k=N i, Y S Z$ or pore and $k \neq j$. Metrics are also presented as either local (v) or bulk values $(\overline{\mathrm{v}})$. Bulk metrics are calculated for the entire volume and are presented as an average value. The local metrics are calculated on a slice-by-slice basis to examine the variation throughout the volume. Avizo's material statistics algorithm was used to calculate slice-by-slice metrics.

Composition.-The anode composition was calculated using Avizo's volume fraction algorithm and TauFactor producing identical results, therefore only one value is presented throughout in the form of a phase-specific volume fraction $\left(\varphi_{j}\right)$.

Tortuosity-factor and percolation.-Tortuosity and percolation was quantified through the production of tortuosity-factors $\left(\tau_{j}\right)$ and percolation values $\left(p_{j}\right)$ using TauFactor for each direction, for each phase, for each of the five thermal cycles resulting in forty-five tortuosity-factors and forty-five percolation values.

Particle size.-The particle sizes were assessed through the quantification of particle Feret diameters using ImageJ software $\left(\emptyset_{j}\right)$. The particle size distribution is presented in the form of a particle Feret diameter histogram for each phase, for each tomogram.

Triple-phase boundaries.-The percentage of percolated TPBs $\left(p_{T P B}\right)$ and the local TPB density $\left(\rho_{T P B}\right)$ values were quantified with the use of two methods as discussed by Cooper et al. ${ }^{30}$ and Lu et al. ${ }^{29}$ The percolated TPBs densities were calculated for each thermal cycle using MATLAB as discussed by Golbert et al. ${ }^{32}$

Particle surface area.-The volume specific surface area $\left(\mathrm{A}_{\mathrm{j}}\right)$ of each particle was quantified with use of the TauFactor application. Values were produced for each phase for each of the five tomograms. Every area value reported is volume specific.

Interfacial contact area.- - The volume specific interfacial contact area $\left(\mathrm{A}_{\mathrm{j}, \mathrm{k}}\right)$ for Ni-YSZ, Ni-pore and pore-YSZ were also assessed using TauFactor and MATLAB.
4D Analysis. - To directly compare each dataset while maintaining statistical representation a sub-volume (ca. $367 \times 300 \times 200$ voxels) from the exact same region of interest (ROI) was removed from each tomogram allowing 4D analysis (3 spatial dimensions plus time).

$\boldsymbol{R V E}$ analysis.-A representative volume element (RVE) analysis was conducted for each study. RVEs computed from the first thermal cycle are presented in Figure 2 for the composition, pore-size, $\mathrm{Ni}$ YSZ contact and TPB density as examples. The RVE analysis was conducted by calculating the chosen variable for a sample volume of a single slice then increasing the sample volume by one slice at a time until the full ROI is investigated, i.e. a constant area, growing volume analysis.

\section{Results}

Three-phase segmentation.-The electrochemical performance is assessed indirectly via the quantification of several microstructural parameters. ${ }^{33,34}$ For instance, the Tortuosity factor would be expected to influence ohmic impedance in the solid phases and diffusion impedance in the gas phase; whereas, particle size and interfacial contact would be expected influence the TPB density which, in turn, would influence the activation overpotential. In order to extract these parameters, the three material phases must first be segmented.

The pore, metal and ceramic networks are displayed in Figure 3 with accompanying local volume fractions presented slice-by-slice for the three phases. The bulk composition values presented here are typical of an SOFC anode: $0.35: 0.28: 0.37$ for $\bar{\varphi}_{N i}: \bar{\varphi}_{Y S Z}: \bar{\varphi}_{\text {Pore }}{ }^{6,15}$ Furthermore, minimal change is seen in the composition of the anode throughout the thermal cycling: on average, the ceramic increased by $0.5 \mathrm{vol} \%$ whereas the $\mathrm{Ni}$ and pore decreased and increased by $3.4 \mathrm{vol} \%$ and $2.9 \mathrm{vol} \%$ respectively. The variation in the ceramic content is negligible as expected due to the stability of 8YSZ within these conditions. The compositional changes within the Ni and pore volume fractions are slightly larger and may be explained by the mobility of $\mathrm{Ni}$ at elevated temperatures; $\mathrm{Ni}$ may leave/enter the ROI to/from the external volume. However, variations remain minor and may also be due to the sensitivity of the segmentation. Therefore it is concluded that, under a sufficiently reducing atmosphere, the anode composition remains relatively unchanged throughout several operational thermal cycles when evaluated at this length scale.

Transport tortuosity-factor and percolation.-A single flux density map for the initial porous structure is presented as an example and as a reference for the spatial orientations (Figure 4). The metal, ceramic and pore tortuosity-factors and percolation percentages in the three orientations are presented in Figures 5a-5c and Figures 5d-5f respectively and are tabulated in Tables I-III. The tortuosity-factor values and phase percolation percentages found here are comparable 
a)

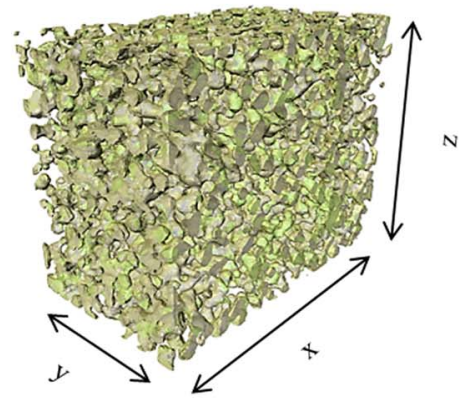

d) Thermal cycle 1

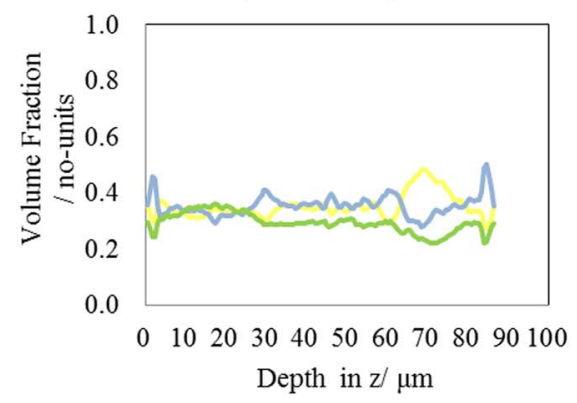

g) Thermal cycle 4

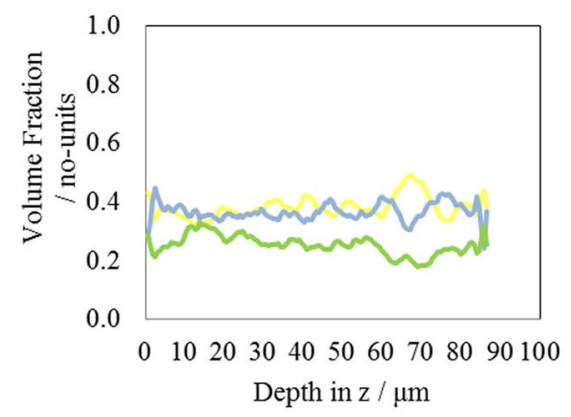

b)

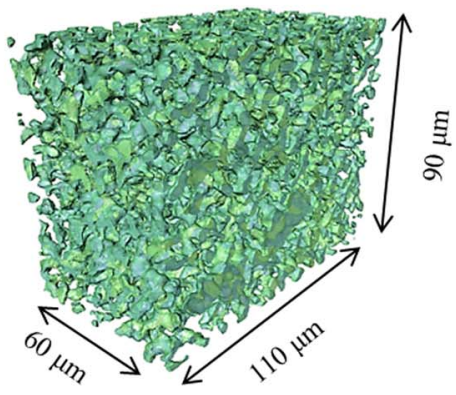

e) Thermal cycle 2

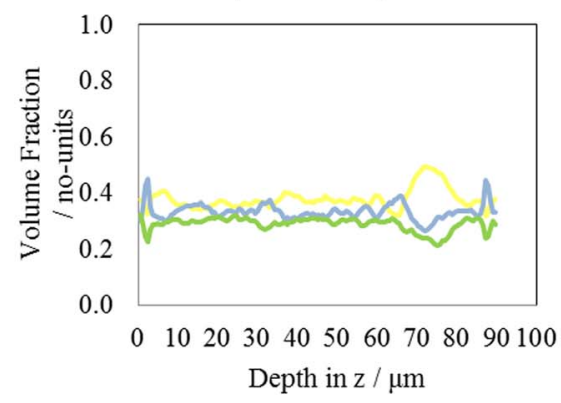

h) Thermal cycle 5

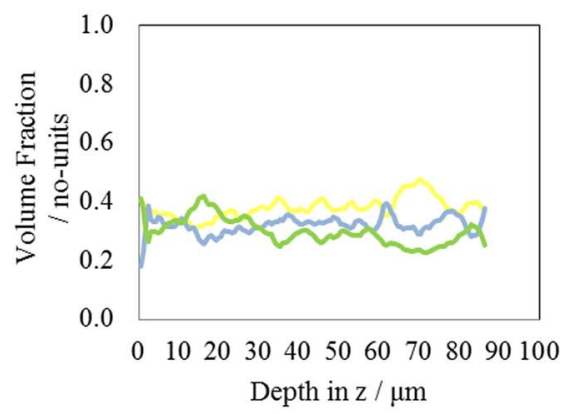

c)

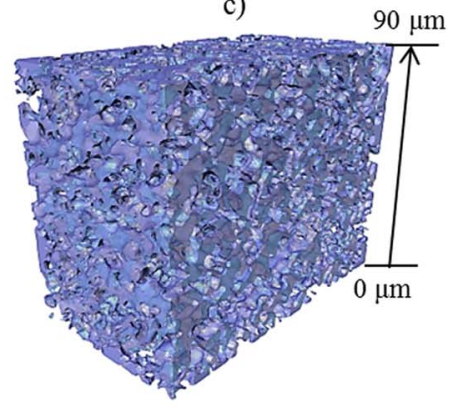

f) Thermal cycle 3

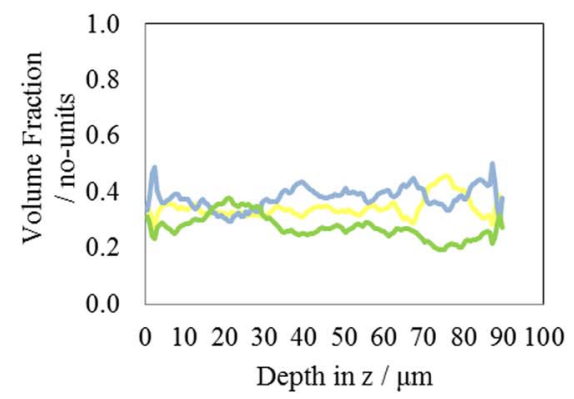

Figure 3. The three-phase segmentation of a Ni-YSZ SOFC anode using X-ray micro-CT: a) pore, b) Ni and c) YSZ 3D phase volumes and d-h) the slice-by-slice compositional volume fraction for the three phases for cycles $1-5$.

a)

b)

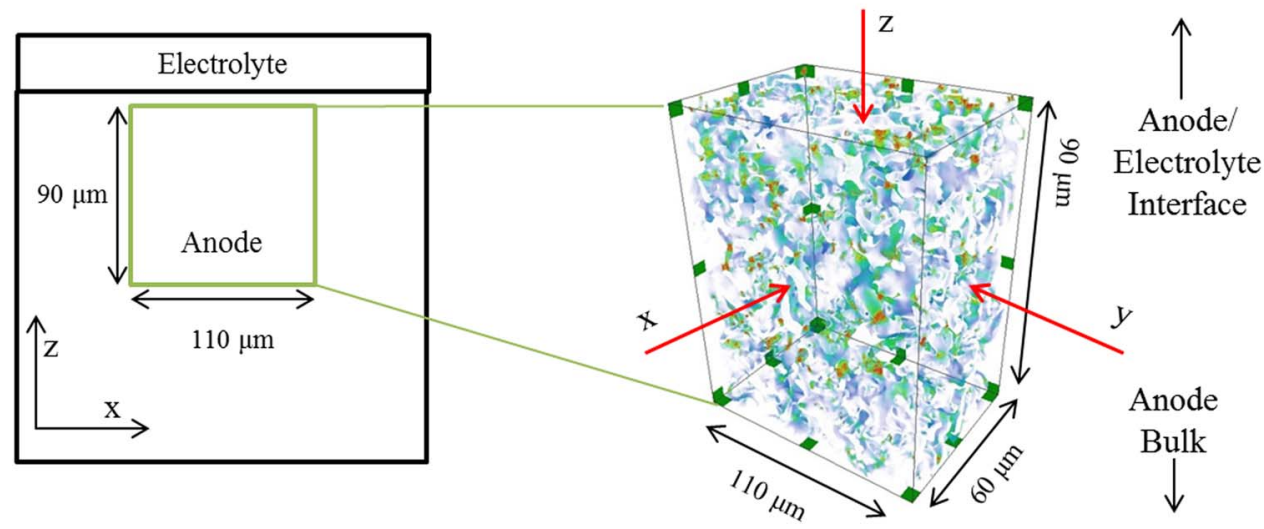

Figure 4. Extracting tortuosity-factor data for the three phases (Ni, YSZ and pore), in the three orientations (x, y and z), for the five thermal cycles: a) a schematic for the spatial reference of the sub-volume analyzed with accompanying b) initial pore-phase flux density map where red regions represent tortuous bottlenecks and blue regions represent openings. 
a)

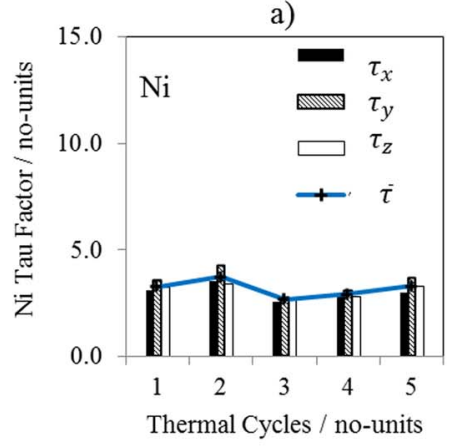

d)

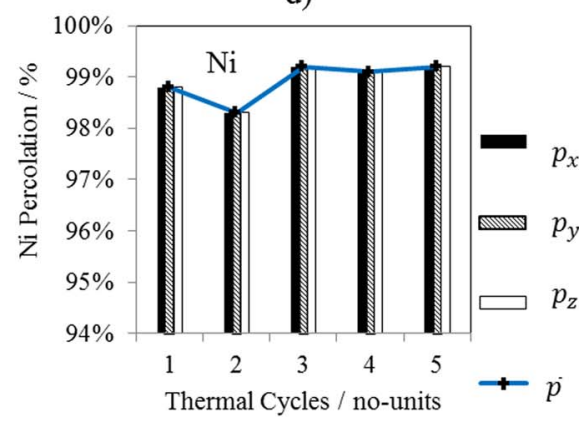

b)

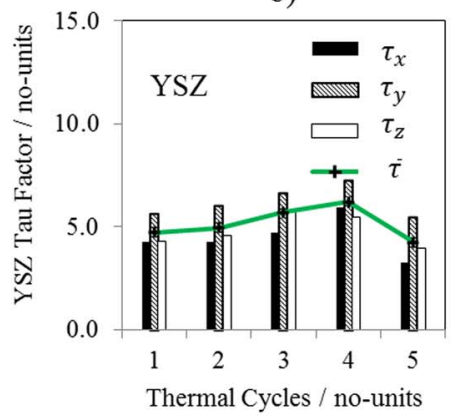

e)

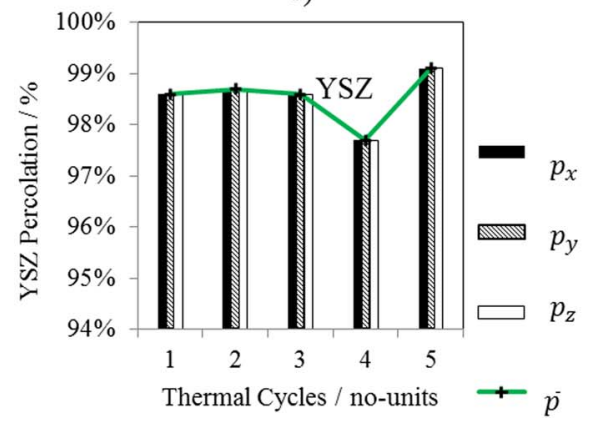

c)

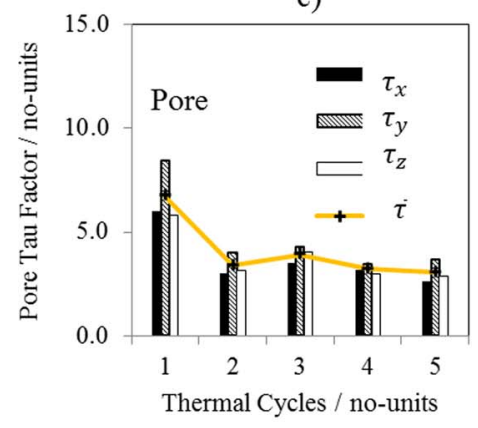

f)

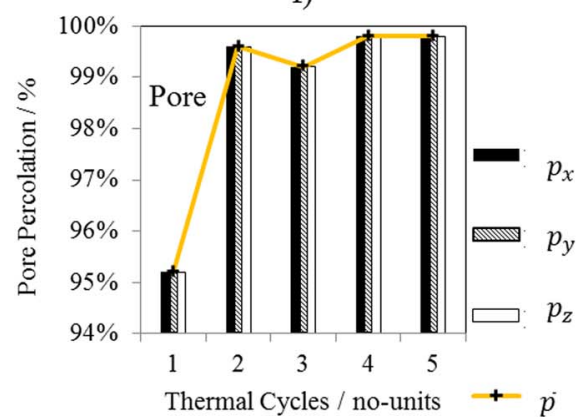

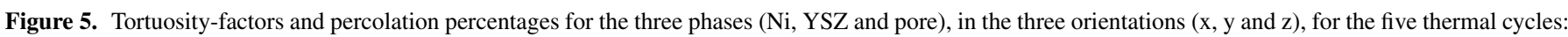
$\mathrm{a}-\mathrm{c}$ ) tortuosity-factor values and $\mathrm{d}-\mathrm{f}$ ) percolation percentages with average values plotted as lines across each bar chart.

Table I. Tortuosity-factor values for Ni, YSZ and pore phases within an SOFC anode throughout five operational thermal cycles and in the three spatial orientations: $x, y$ and $z$ and presented to 2 d.p.

\begin{tabular}{|c|c|c|c|c|c|c|c|c|c|}
\hline \multirow[b]{2}{*}{ Thermal Cycles } & \multicolumn{3}{|c|}{ Tortuosity-Factor in $\mathrm{x} /$ no-units } & \multicolumn{3}{|c|}{ Tortuosity-Factor in y/no-units } & \multicolumn{3}{|c|}{ Tortuosity-Factor in z/no-units } \\
\hline & $\mathrm{Ni}$ & YSZ & Pore & $\mathrm{Ni}$ & YSZ & Pore & $\mathrm{Ni}$ & YSZ & Pore \\
\hline 1 & 3.09 & 4.28 & 6.01 & 3.55 & 5.67 & 8.41 & 3.21 & 4.27 & 5.79 \\
\hline 3 & 2.57 & 4.72 & 3.50 & 2.73 & 6.66 & 4.25 & 2.75 & 5.76 & 4.01 \\
\hline 4 & 2.90 & 5.93 & 3.20 & 3.05 & 7.27 & 3.46 & 2.81 & 5.47 & 2.99 \\
\hline 5 & 2.98 & 3.27 & 2.63 & 3.64 & 5.51 & 3.68 & 3.27 & 3.97 & 2.88 \\
\hline
\end{tabular}

Table II. Percentage percolation values for Ni, YSZ and pore phases within an SOFC anode throughout five operational thermal cycles and in the three spatial orientations: $x, y$ and $z$ and presented to 1 d.p.

\begin{tabular}{|c|c|c|c|c|c|c|c|c|c|}
\hline \multirow[b]{2}{*}{ Thermal Cycles } & \multicolumn{3}{|c|}{ Percolation in $\mathrm{x} / \%$} & \multicolumn{3}{|c|}{ Percolation in $\mathrm{y} / \%$} & \multicolumn{3}{|c|}{ Percolation in $\mathrm{z} / \%$} \\
\hline & $\mathrm{Ni}$ & YSZ & Pore & $\mathrm{Ni}$ & YSZ & Pore & $\mathrm{Ni}$ & YSZ & Pore \\
\hline 1 & 98.8 & 98.6 & 95.2 & 98.8 & 98.6 & 95.2 & 98.8 & 98.6 & 95.2 \\
\hline 3 & 99.2 & 98.6 & 99.2 & 99.2 & 98.6 & 99.2 & 99.2 & 98.6 & 99.2 \\
\hline 4 & 99.1 & 97.7 & 99.8 & 99.1 & 97.7 & 99.8 & 99.1 & 97.7 & 99.8 \\
\hline 5 & 99.2 & 99.1 & 99.8 & 99.2 & 99.1 & 99.8 & 99.2 & 99.1 & 99.8 \\
\hline
\end{tabular}

Table III. Tortuosity-factor and percolation values for Ni, YSZ and pore phases within an SOFC anode throughout five operational thermal cycles averaged in the three spatial orientations: $x, y$ and $z$.

Average Percolation/\%

\begin{tabular}{|c|c|c|c|c|c|c|}
\hline \multirow[b]{2}{*}{ Thermal Cycles } & & \\
\hline & $\mathrm{Ni}$ & YSZ & Pore & $\mathrm{Ni}$ & YSZ & Pore \\
\hline 1 & 98.8 & 98.6 & 95.2 & 3.28 & 4.74 & 6.74 \\
\hline 2 & 98.3 & 98.7 & 99.6 & 3.72 & 4.96 & 3.39 \\
\hline 3 & 99.2 & 98.6 & 99.2 & 2.68 & 5.71 & 3.92 \\
\hline 4 & 99.1 & 97.7 & 99.8 & 2.92 & 6.22 & 3.22 \\
\hline 5 & 99.2 & 99.1 & 99.8 & 3.30 & 4.25 & 3.06 \\
\hline
\end{tabular}


a)

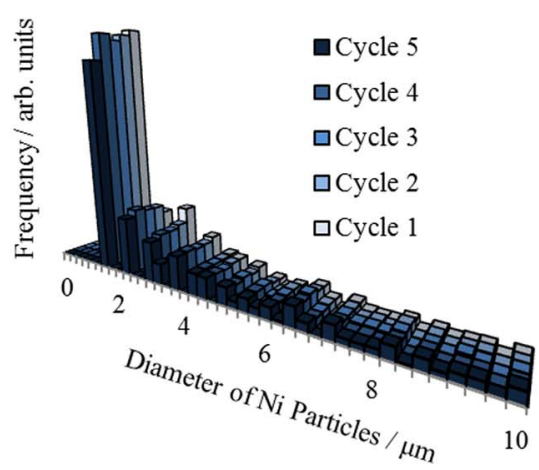

d)

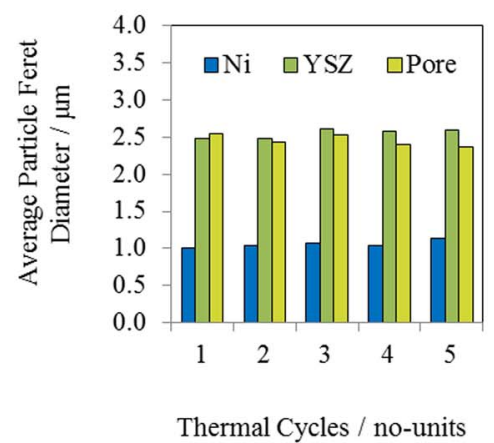

b)

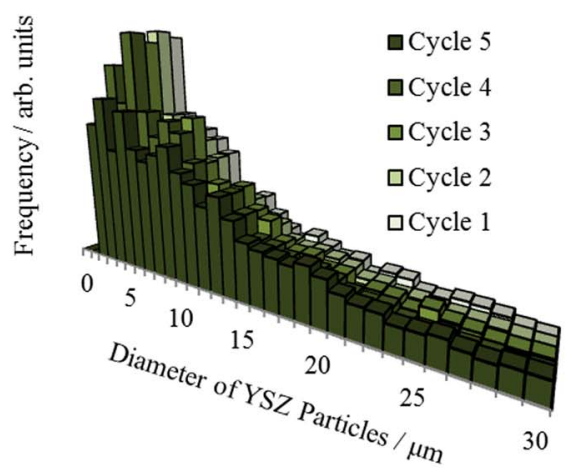

e)

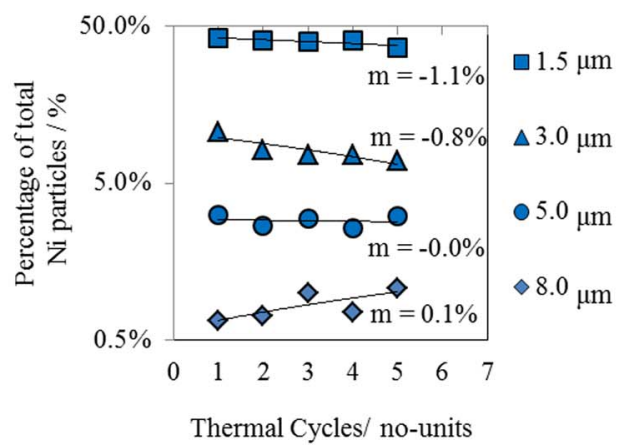

c)

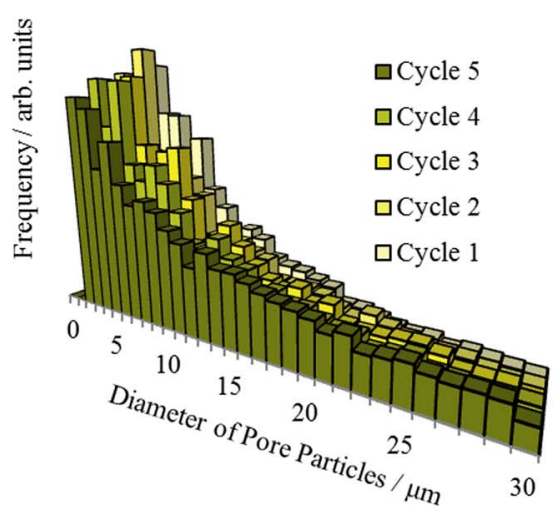

f)

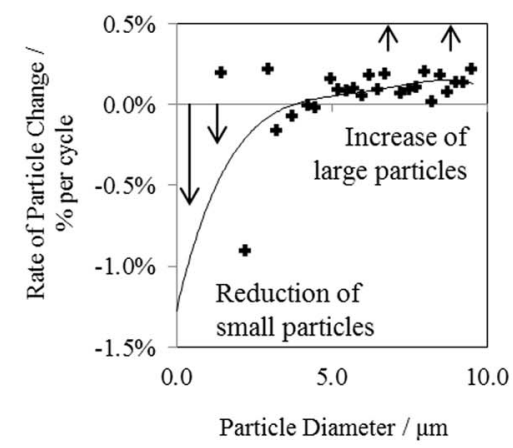

Figure 6. Particle size analysis of the Ni (blue), YSZ (green) and pore (yellow) with each thermal cycle: histograms of the particle Feret diameters for a) Ni, b) YSZ and c) pore, d) the average particle size with thermal cycling, e) the percentage of Ni particles between $1.5-8.0 \mu \mathrm{m}$ with the rate of change with thermal cycling indicated by the gradients ' $m$ ' and, f) $m$ plotted for a range of particle sizes from $1.5-10.0 \mu \mathrm{m}$.

to that which have been presented in the literature previously and are typical of SOFC anodes. ${ }^{10,35}$

The average tortuosity-factor values for $\mathrm{Ni}$ and $\mathrm{YSZ}$ remain relatively constant throughout the operational thermal cycling: $\Delta \bar{\tau}_{N i}=$ +0.02 and $\Delta \bar{\tau}_{Y S Z}=-0.49$. However, the pore-phase tortuosityfactor reduces substantially $\Delta \bar{\tau}_{\text {Pore }}=-3.68$, accompanied by a ca. $4 \%$ increase in percolation. The Ni and YSZ percolation percentages remain high (above $97 \%$ ) throughout. The majority of the reduction in the pore-phase $\tau$ occurs after the first thermal cycle; the pore-phase tortuosity-factor reduction after the first cycle is $\Delta \bar{\tau}_{\text {Pore }}=-3.35$, ca. $91 \%$ of the total reduction after cycling. The alterations in the pore-phase may be explained by $\mathrm{Ni}$ mobility during the first lowramp thermal cycle; further investigation with the use of advanced computational techniques such as digital volume correlation (DVC) ${ }^{36}$ may confirm this but is beyond the scope of this paper.

Considering the different orientations, all phases were percolated to a similar degree in all directions. However, larger tortuosity-factor values were consistently observed in the y-plane, particularly in the ceramic and pore. This suggests that parallel to the interface, there may be non-uniformities in perpendicular directions. This is contrary to what would be expected in a homogenous cell; directions $\mathrm{x}$ and $\mathrm{y}$ would be assumed arbitrary in a spatially homogenous microstructure, whereas $\mathrm{z}$ is often graded intentionally in order to supply favorable microstructures at different distances from the anode/electrolyte interface, such as the anode functional (AFL) and support layers (ASL). Therefore, inhomogeneity between the $\mathrm{x}$ and $\mathrm{y}$ planes suggests the existence of structural defects, possibly introduced during fabrication.

Ultimately only minor variation is observed in the Ni and YSZ tortuosity-factor values and percolation percentages throughout ther-

\begin{tabular}{|c|c|c|c|c|c|}
\hline & \multicolumn{5}{|c|}{ Thermal Cycles } \\
\hline & 1 & 2 & 3 & 4 & 5 \\
\hline $\mathrm{Ni}$ & 1.00 & 1.03 & 1.06 & 1.04 & 1.14 \\
\hline YSZ & 2.48 & 2.49 & 2.61 & 2.57 & 2.60 \\
\hline Pore & 2.55 & 2.43 & 2.54 & 2.40 & 2.36 \\
\hline
\end{tabular}

mal cycling, and the same is observed within the pore-phase after stabilising during low ramp-rates. However consistent differences between the orthogonal directions within the anode suggest nonuniformities parallel to the interface.

Particle size analysis. - The particle Feret diameters for each of the three phases are presented in Figure 6 and are tabulated in Table IV. Particle size histograms indicate that Ni particles have a small range of diameters and are also relatively small in size but remain characteristic of an SOFC microstructure; ${ }^{3,10}$ throughout cycling the average $\mathrm{Ni}$ diameter ranges from $\bar{\varphi}_{N i}=1.00 \mu \mathrm{m}$ to $1.14 \mu \mathrm{m}$. Whereas, the pore and ceramic particles present larger, but similar, diameters throughout, ranging from $\bar{\varphi}_{\text {pore }}=2.36 \mu \mathrm{m}$ to $2.55 \mu \mathrm{m}$ and $\bar{\varphi}_{Y S Z}=2.48 \mu \mathrm{m}$ to $2.61 \mu \mathrm{m}$, respectively.

Inspecting the variation in the percentage of $\mathrm{Ni}$ particles smaller than 1.5, 3.0, 5.0 and $8.0 \mu \mathrm{m}$ with each thermal cycle (Table V), it is concluded that there is a reduction in the percentage of smaller particles, a relatively consistent percentage of medium particles and a 
a)

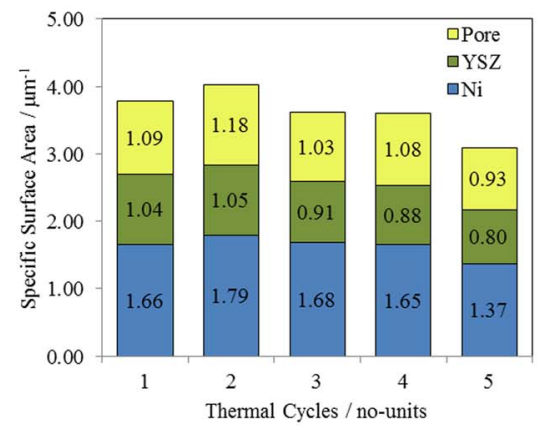

b)

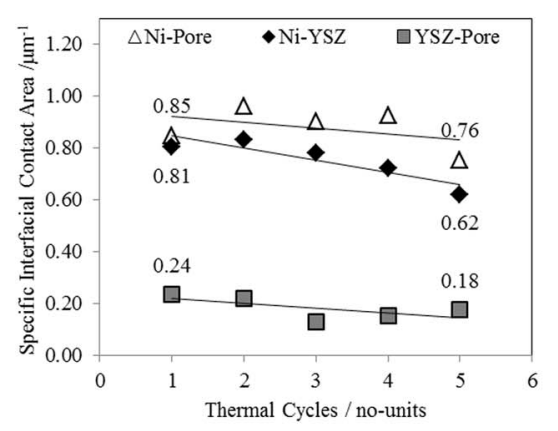

c)

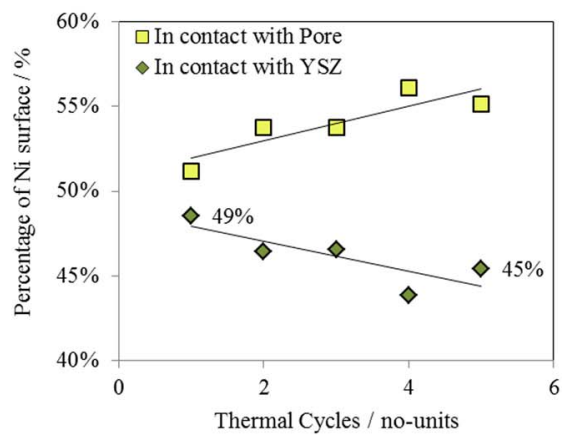

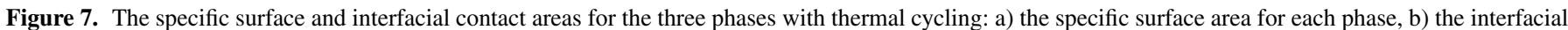
contact between the three phases and, c) the change in the percentage of the Ni surface which is in contact with either YSZ or pore.

\begin{abstract}
Table V. The percentage of total Ni particles from an SOFC anode with Feret diameters of 1.5, 3.0, 5.0 or $8.0 \mu \mathrm{m}$ for each thermal cycle.
\end{abstract}

Thermal Cycles

\begin{tabular}{cccccc}
\cline { 2 - 6 } Feret Diameter & 1 & 2 & 3 & 4 & 5 \\
\hline $1.5 \mu \mathrm{m}$ & $41.5 \%$ & $40.6 \%$ & $39.5 \%$ & $40.5 \%$ & $36.0 \%$ \\
$3.0 \mu \mathrm{m}$ & $10.5 \%$ & $8.1 \%$ & $7.6 \%$ & $7.6 \%$ & $6.9 \%$ \\
$5.0 \mu \mathrm{m}$ & $3.1 \%$ & $2.7 \%$ & $3.0 \%$ & $2.6 \%$ & $3.1 \%$ \\
$8.0 \mu \mathrm{m}$ & $0.7 \%$ & $0.7 \%$ & $1.0 \%$ & $0.8 \%$ & $1.1 \%$
\end{tabular}

subtle increase in the percentage of large particles; the rate of growth of large Ni particles (ca. $0.1 \%$ ) is an order of magnitude lower than the rate of loss of small $\mathrm{Ni}$ particles (ca. 1.0\%). This is quite typical of sintering mechanisms because it requires several smaller particles to combine in order to form larger particles; therefore there will inherently be fewer large particles created during sintering, compared to the number of small particles removed. Smaller particles also have a larger area-to-volume ratio which results in a higher system energy and lower stability.

Although the Ni particles are observed to sinter, the ramp-rate appears to have a negligible effect on the degree of coarsening due to the relatively short periods at temperature (under 10 hours), compared to long operational dwell times which are often quoted in the thousands of hours. During long-term operation considerable agglomeration of the Ni particles is expected to occur; the average Ni particle diameter can be expected to grow with a logarithmic profile during operation. ${ }^{11,37}$

Surface and interfacial contact areas.-The volume specific surface areas for the three phases and their volume specific interfacial contact areas are presented in Figure 7. It can be seen that there is a general reduction in particle surface area with thermal cycling; the total surface area after one cycle is $\overline{\mathrm{A}}_{\text {total }}=3.79 \mu \mathrm{m}^{-1}$ whereas after cycling this reduces to $\overline{\mathrm{A}}_{\text {total }}=3.10 \mu \mathrm{m}^{-1}$. Ni consistently presents the largest specific surface areas ranging from $\overline{\mathrm{A}}_{N i}=1.79 \mu \mathrm{m}^{-1}$ to $1.37 \mu \mathrm{m}^{-1}$ likely due to the smaller particle size, but comparable to values presented in literature previously. ${ }^{3}$ While the large particles of pore and YSZ range from $\overline{\mathrm{A}}_{\text {pore }}=1.18 \mu \mathrm{m}^{-1}$ to $0.93 \mu \mathrm{m}^{-1}$ and $\overline{\mathrm{A}}_{Y S Z}=1.05 \mu \mathrm{m}^{-1}$ to $0.80 \mu \mathrm{m}^{-1}$.

Inspecting the particle-particle volume specific contact area it can be seen that the ceramic and pore share significantly less contact area than the metal and ceramic and, the metal and pore. The ceramic and pore contact area ranges from $0.24 \mu \mathrm{m}^{-1}$ to $0.18 \mu \mathrm{m}^{-1}$, whereas the metal and ceramic, and metal and pore range from $0.81 \mu \mathrm{m}^{-1}$ to $0.62 \mu \mathrm{m}^{-1}$ and $0.85 \mu \mathrm{m}^{-1}$ to $0.76 \mu \mathrm{m}^{-1}$, respectively. The ceramicpore and metal-pore contact is relatively consistent throughout the thermal cycling, reducing by only $0.06 \mu \mathrm{m}^{-1}$ and $0.09 \mu \mathrm{m}^{-1}$, respec- tively. Whereas although initially similar to values presented in the literature, ${ }^{29}$ the metal-ceramic contact reduces by $0.19 \mu \mathrm{m}^{-1}$, over triple the ceramic-pore losses and double the metal-pore losses.

It is possible that there are two mechanisms responsible for the reduction in Ni-YSZ contact during thermal cycling: firstly, grain growth leads to Ni diffusing into the metal bulk, with a general loss of Ni surface area observed as it agglomerates, and secondly, the mismatch in the Ni and YSZ thermal expansion results in deformation consistent with Timoshenko's model. ${ }^{38}$ The microscopic implications of thermal expansion mismatch between single parties, have been explored elsewhere. ${ }^{19,20}$ Moreover, as discussed previously, the agglomeration effects observed here during operational cycling are minor compared to operational dwelling, suggesting TEC mismatch is the dominant mechanism responsible for degradation during cycling.

Finally, the delamination of the metal can be quantified by the reduction of the $\mathrm{Ni}$ surface which is in contact with the ceramic. The Ni-YSZ contact reduces by approximately $5 \%$ after the five thermal cycles. However, although delamination occurs consistently after each thermal cycle the degree of delamination appears to not be affected by the thermal ramp rate; a similar magnitude of metal-ceramic delamination is observed after each thermal cycle, a reduction of approximately $1 \%$ per cycle.

Triple-phase boundaries.-Figure 8 displays the TPB map for the same ROI throughout operational thermal cycling. From a purely qualitative inspection of Figure $8 \mathrm{a}$, it is clear that there is a reduction in the $\rho_{T P B}$ throughout the sample, confirmed quantitatively in Figure $8 \mathrm{~b}$; the reaction site density reduces from $0.93 \mu \mathrm{m}^{-2}$ to $0.57 \mu \mathrm{m}^{-2}$ after five thermal cycles, a reduction of ca. $-0.07 \mu \mathrm{m}^{-2}$ per thermal cycle. Deviations between $\bar{\rho}_{T P B}$ values obtained from TauFactor and MATLAB were negligible throughout, under $1 \%$. The TPB percolation was also extracted for each thermal cycle; the first thermal cycle delivered a TPB percolation of $88 \%$, which increased substantially after the following thermal cycle and remained consistent until the final cycle, at around $92 \%$. As speculated previously, although the sintering of Ni particles is subtle during operational start-up and shutdown this may provide sufficient mobility to reduce the number of restricted and tortuous pore networks, increasing the population of percolated TPB reaction sites. Values quoted within the literature for the $\bar{\rho}_{T P B}$ and $p_{T P B}$ can be varied; $\bar{\rho}_{T P B}$ values are typically reported to be between $1-10 \mu \mathrm{m}^{-2}, 3,7,10,15$ whereas $p_{T P_{B}}$ percentages can vary between $50-90 \% .^{7,10}$ Therefore this anode is on the lower end of the reported TPB values compared to the literature but it has also been found that there is a dependency on the resolution, ${ }^{39}$ therefore direct comparisons to literature values obtained using a different resolution cannot be applied.

Another mechanism which is observed is that the TPB density is consistently highest toward the electrolyte, even after thermal cycling. This is likely due to an anode functional layer deposited during fabrication. Although, the region of peak TPB density not only reduced 
a)

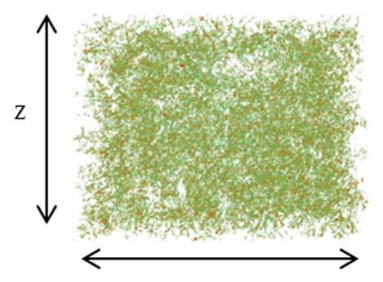

$\mathrm{x}$

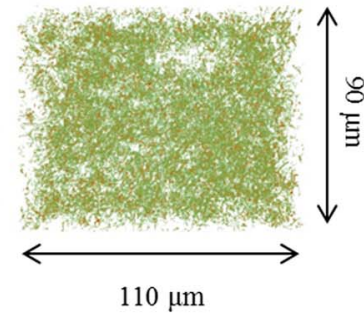

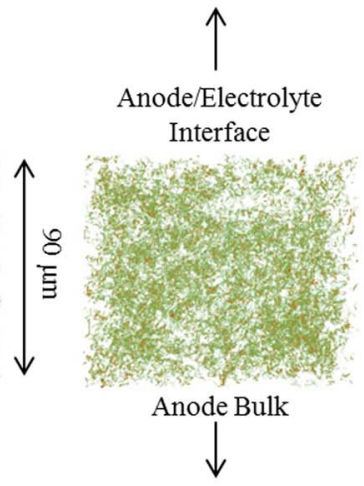

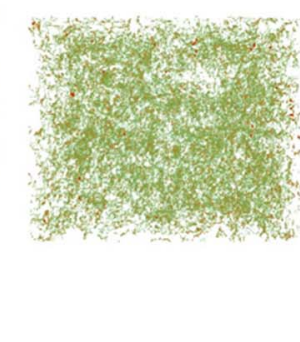

$90 \mu \mathrm{m}$

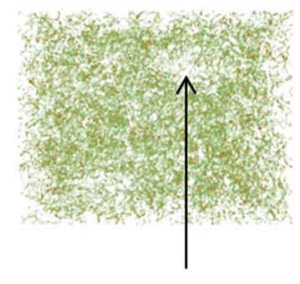

Heterogeneous Pore

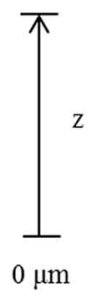

$0 \mu \mathrm{m}$ b)

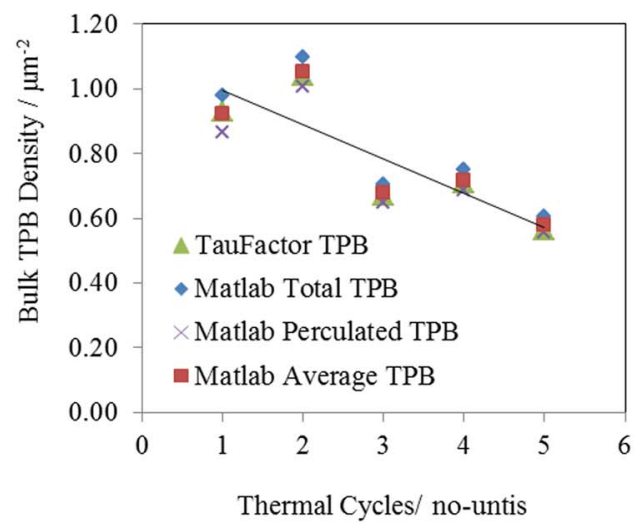

c)

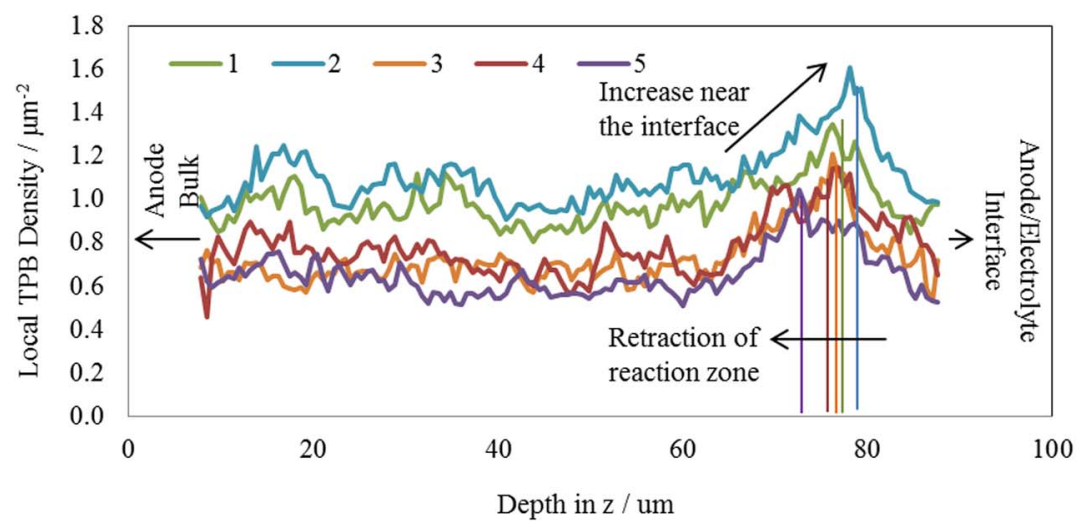

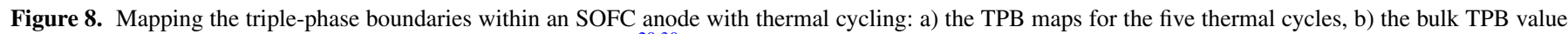
within the ROI, with each thermal cycle from several techniques, ${ }^{29,30}$ and c) the local TPB value for each thermal cycle.

in magnitude but also broadens and retracts away from the interface into the bulk (Figure 8c). This suggests that the electrochemical reaction site density increases inhomogeneity during cycling, reducing the distinction between the functional and bulk anode layers. Literature has previously reported the reduction of reaction sites near the anode/electrolyte interface along with the retraction of the reaction zone. ${ }^{11}$

Thermal cycling degradation.-To inspect the effects of thermal cycling, Figure 9 displays the first (black) and last (red) data collected from the SOFC anode for a slice-by-slice comparison. All metrics retained a similar line profile after thermal cycling with either very subtle changes or a net shift in magnitude. The compositional data displays minimal change after cycling for all three phases, inherently retaining very similar line profiles. Whereas the TPB density displays a net reduction throughout the sample, as does the Ni-YSZ interfacial contact.

In order to investigate the influence of the Ni particle sintering and the delamination of the $\mathrm{Ni}$ and YSZ, the reduction in the NiYSZ specific surface contact and the reduction in the number of small particles are both plotted with respect to the distance in the anode, with the loss of TPB density overlaid for both. From Figures 10a and 10c it is clear that there is a close dependency upon both the degree of Ni particle sintering and Ni-YSZ delamination with respect to the loss in TPB density. This has been previously predicted with the use of advanced computational models based upon morphological operations applied to X-ray CT data of tubular SOFC anodes. ${ }^{29}$ Also presented in Figure 10 is the reduction of the TPB density with respect to the Ni-YSZ contact and reduction of small Ni particles (Figures 10b and 10d). From the figure it is clear that the degree of delamination is more influential on the loss of TPB density than the degree of sintering however, as sintering effects become more severe during long-duration operational dwelling, this may reverse as the population of small particles diminishes.

In order to investigate the effects of operational start-up time the peak operating temperature and thermal cooling rates were kept consistent. Future studies may investigate the effects of the peak operating temperature and thermal cooling rates but these results suggest that the thermal heating-rate does not have a significant effect on the interaction between Ni and YSZ particles at a microscopic scale whereas, the number of thermal cycles does appear to influence the degree of delamination and should therefore be minimized. However, two points should be considered before reducing the number of thermal cycles: firstly, reducing the number of thermal cycles may increase the duration at temperature, possibly intensifying what are currently insignificant sintering effects, secondly the macroscopic implications of high ramp-rates may be more prominent i.e. delamination of the electrolyte from the anode. ${ }^{17}$

\section{Conclusions}

This work concludes the first piece of a two-part study on thermally induced degradation within SOFCs. The properties which are thought to influence the electrochemical performance within SOFC anodes have been quantified and monitored for the same region of interest throughout the operational thermal cycling of a Ni-YSZ cermet anode sample from an anode-supported solid oxide half-cell.

Through the use of the electrolyte and surrounding space as greyscale-fiducial references each dataset was segmented with sufficient confidence for comparison. It is seen that the compositional volume fractions follow very similar profiles within the anode throughout thermal cycling, with the ceramic content deviating by negligible amounts and minor variation in the $\mathrm{Ni}$ and pore composition possibly being attributed to the mobility of $\mathrm{Ni}$ at elevated temperatures. 
a)

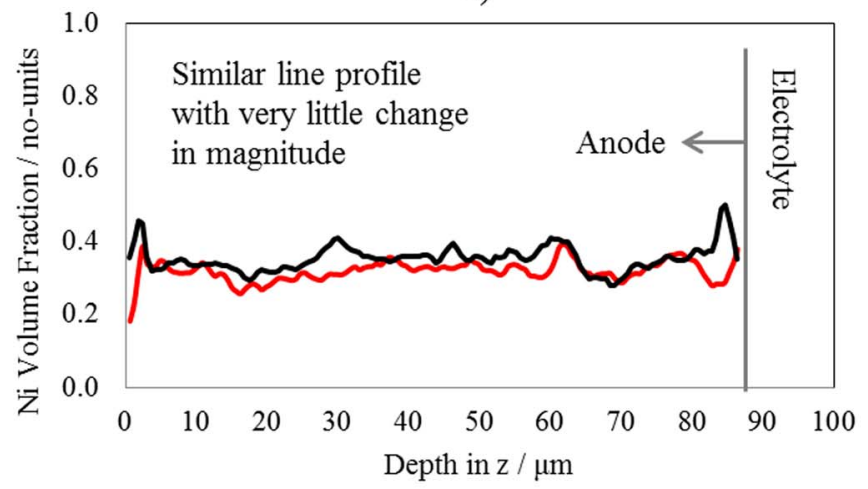

b)

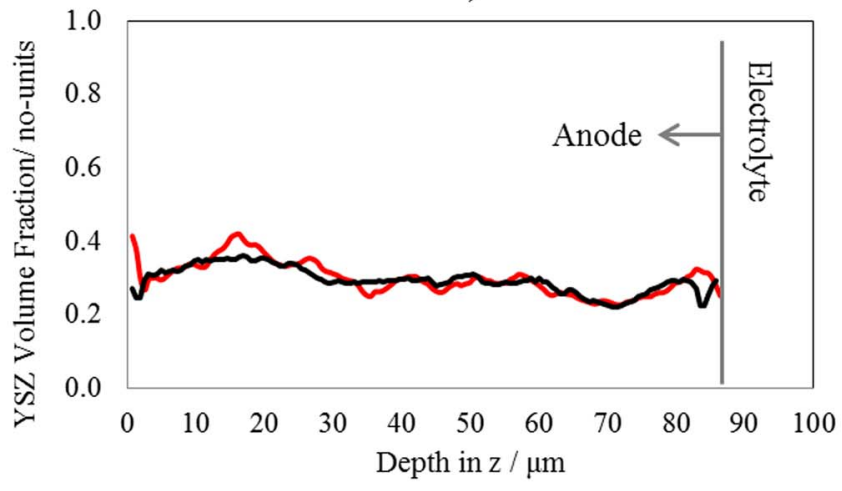

c)

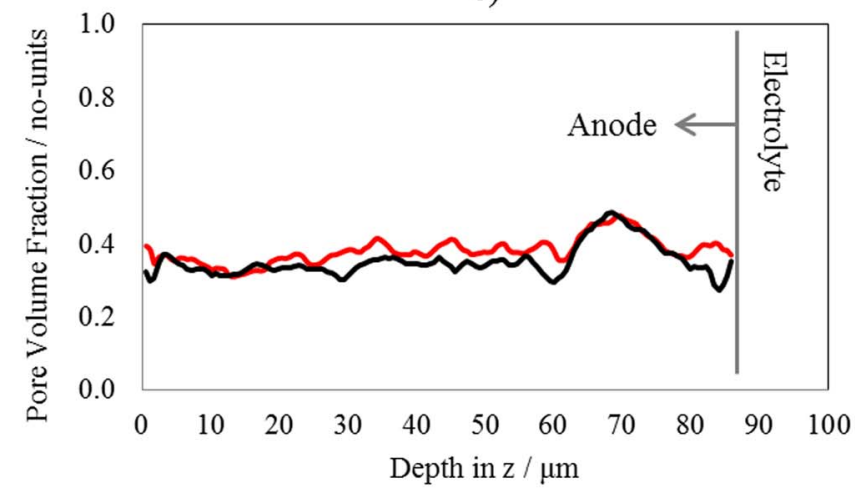

d)

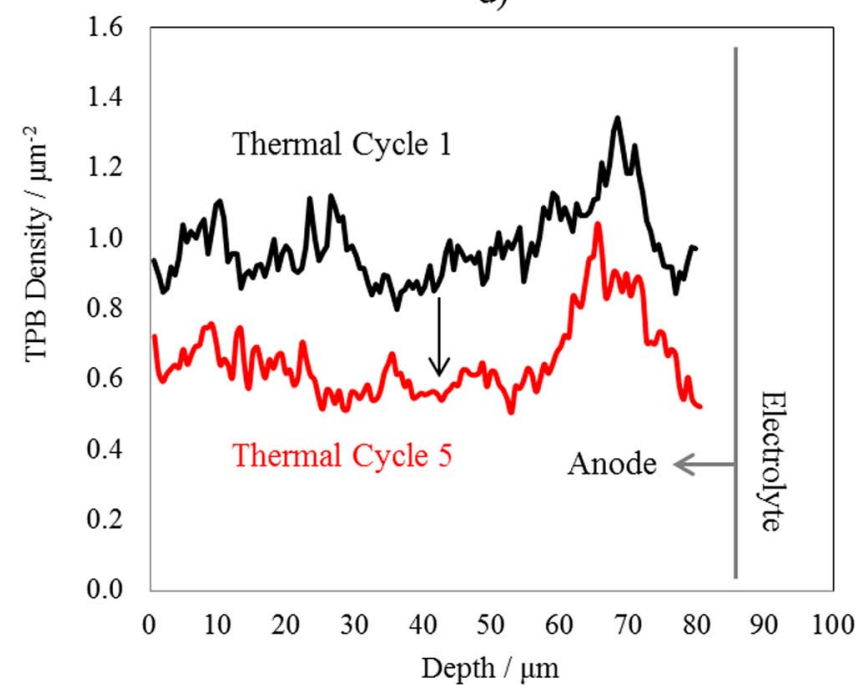

e)

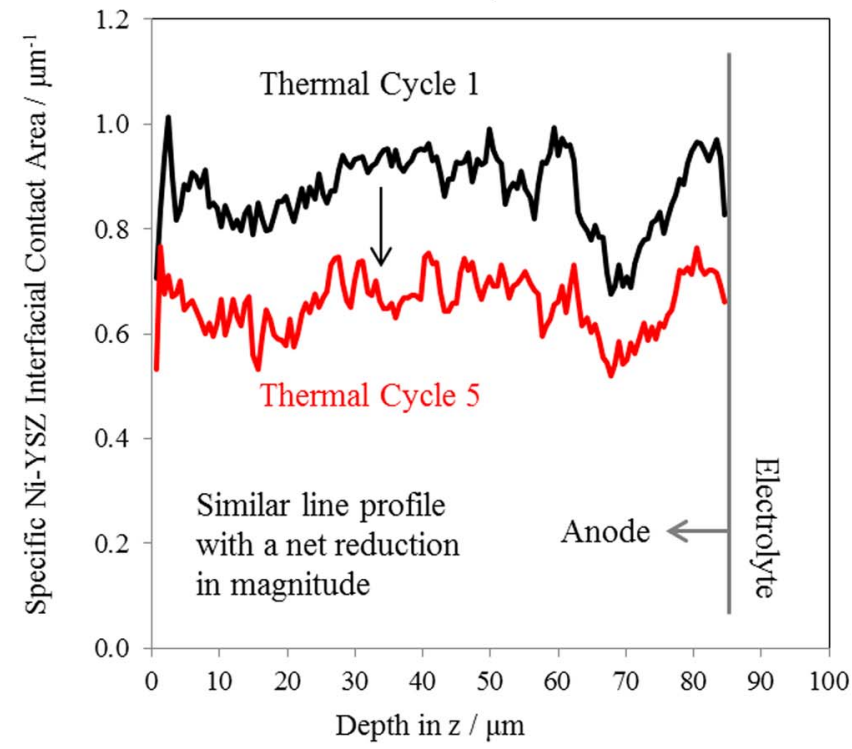

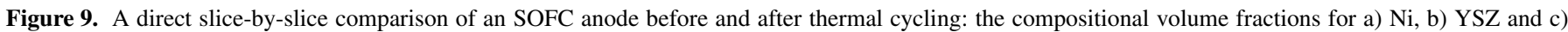
pore, d) TPB density and, e) Ni-YSZ specific interfacial contact area.

Alignment of the sample produced a direct comparison between datasets allowing the correlation of degradation mechanisms to prominent structural metrics such as particle size, tortuosity-factor, percolation and surface area. The reduction in the number of small $\mathrm{Ni}$ particles is observed with thermal cycling although; the sintering effects are minimal compared to the long-duration operational dwelling. Substantial reduction is observed in the pore-phase tortuosity-factor after a low ramp-rate thermal cycle, accompanied by a significant $4 \%$ increase in percolation. This evolution is attributed to the Ni mobility due to a longer duration at temperature. Although the tortuosityfactor values in the $\mathrm{x}$ - and $\mathrm{z}$-planes displayed very similar values for all datasets, consistent deviation is observed in the y-plane suggesting non-uniform degradation mechanisms parallel to the anode/electrolyte interface, possibly due to a fabrication defect. The delamination of the $\mathrm{Ni}$ and YSZ appears to be independent of the thermal ramp rate; a similar magnitude of approximately $1 \%$ reduction of the Ni-YSZ contact surface area is observed after each thermal cycle. Finally the effects of
$\mathrm{Ni}$ sintering and Ni-YSZ delamination on the loss of TPB density are assessed on a slice-by-slice basis; both mechanisms correlate closely with the loss in electrochemical performance but for operational thermal cycling, delamination proves more detrimental to electrochemical performance.

This work provides insight into the degradation mechanisms responsible for electrochemical performance losses within SOFC anodes during operational start-up and shut-down. Such knowledge will aid in the mitigation of SOFC degradation ultimately improving device performance and lifetimes.

\section{Acknowledgments}

The authors acknowledge the EPSRC (EP/M014045/1, EP/ P009050/1), the Centre for Doctoral training (EP/L015749/1) and the Royal Academy for Engineering for financial support, access to the VERSA instrument was supported by EPSRC (EP/N032888/1). 
a)

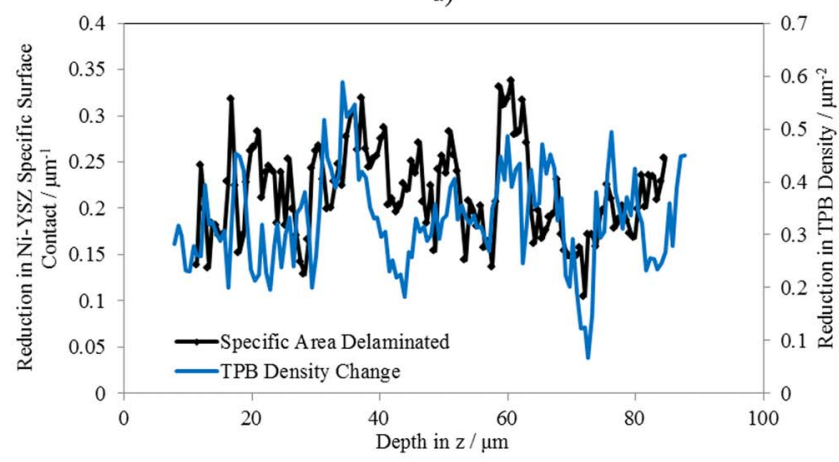

c)

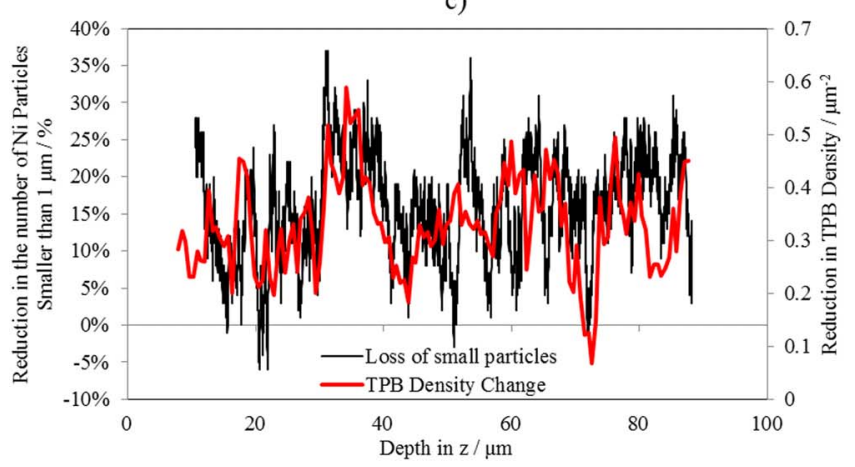

b)

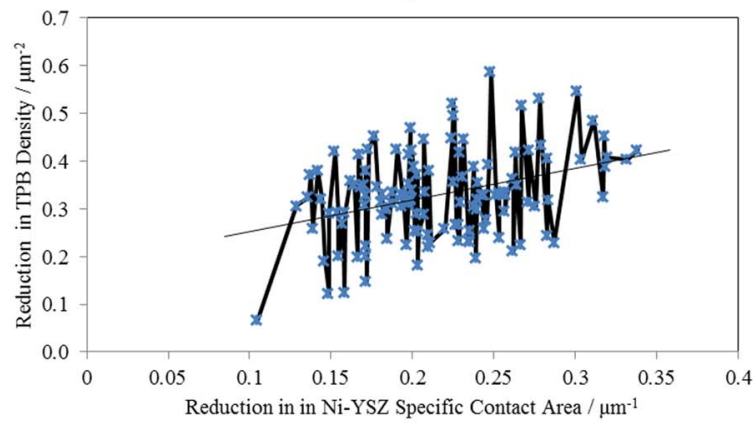

d)

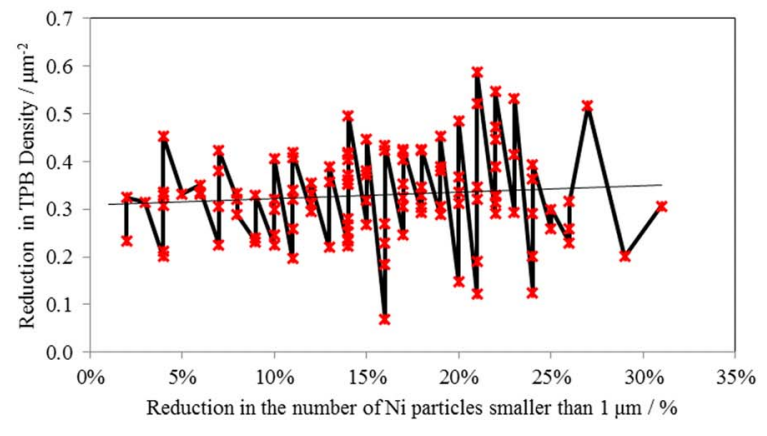

Figure 10. Correlating the delamination and sintering effects to the reduction in the TPB density; a) the reduction in the specific interfacial contact area overlaid with the reduction in the TPB density with respect to the depth toward the anode/electrolyte interface, b) the reduction in the TPB density plotted with respect to the reduction in the Ni-YSZ contact area, c) the reduction in the number of small particles overlaid with the reduction in the TPB density with respect to the depth toward the anode/electrolyte interface, b) the reduction in the TPB density plotted with respect to the reduction in the number of small Ni particles.

\section{ORCID}

T. M. M. Heenan (10 https://orcid.org/0000-0001-9912-4772

J. B. Robinson (iD https://orcid.org/0000-0002-6509-7769

D. J. L. Brett (10) https://orcid.org/0000-0002-8545-3126

P. R. Shearing (D) https://orcid.org/0000-0002-1387-9531

\section{References}

1. R. M. Ormerod, "Solid oxide fuel cells." Chemical Society Reviews, 32(1), 17 (2003)

2. M. Hanasaki, C. Uryu, T. Daio, T. Kawabata, Y. Tachikawa, S. M. Lyth, Y. Shiratori, S. Taniguchi, and K. Sasaki, "SOFC durability against standby and shutdown cycling." Journal of The Electrochemical Society, 161(9), F850 (2014).

3. Y. Guan, Y. Gong, W. Li, J. Gelb, L. Zhang, G. Liu, X. Zhang, X. Song, C. Xia, Y. Xiong, and H. Wang, "Quantitative analysis of micro structural and conductivity evolution of Ni-YSZ anodes during thermal cycling based on nano-computed tomography." Journal of Power Sources, 196(24), 10601 (2011).

4. W. Bujalski, C. M. Dikwal, and K. Kendall, "Cycling of three solid oxide fuel cell types." Journal of Power Sources, 171(1), 96 (2007).

5. H. Fukunaga, M. Ihara, K. Sakaki, and K. Yamada, "The relationship between overpotential and the three phase boundary length." Solid State Ionics, 86, 1179 (1996).

6. J. R. Wilson, W. Kobsiriphat, R. Mendoza, H. Y. Chen, J. M. Hiller, D. J. Miller, K. Thornton, P. W. Voorhees, S. B. Adler, and S. A. Barnett, "Three-dimensional reconstruction of a solid-oxide fuel-cell anode." Nature materials, 5(7), 541 (2006).

7. P. R. Shearing, J. Gelb, J. Yi, W. K. Lee, M. Drakopolous, and N. P. Brandon, "Analysis of triple phase contact in Ni-YSZ microstructures using non-destructive X-ray tomography with synchrotron radiation." Electrochemistry Communications, 12(8), 1021 (2010).

8. J. Laurencin, R. Quey, G. Delette, H. Suhonen, P. Cloetens, and P. Bleuet, "Characterisation of Solid Oxide Fuel Cell Ni-8YSZ substrate by synchrotron X-ray nanotomography: from 3D reconstruction to microstructure quantification." Journal of Power Sources, 198, 182 (2012).

9. V. Julie, L. Jérôme, C. Peter, B. Pierre, D. Gérard, S. Heikki, and U. V. François, "3D phase mapping of solid oxide fuel cell YSZ/Ni cermet at the nanoscale by holographic X-ray nanotomography." Journal of Power Sources, 243, 841 (2013).

10. J. S. Cronin, Y. C. K. Chen-Wiegart, J. Wang, and S. A. Barnett, "Three-dimensional reconstruction and analysis of an entire solid oxide fuel cell by full-field transmission X-ray microscopy." Journal of Power Sources, 233, 174 (2013).
11. A. Zekri, K. Herbrig, M. Knipper, J. Parisi, and T. Plaggenborg, "Nickel Depletion and Agglomeration in SOFC Anodes During Long-Term Operation." Fuel Cells, 17(3), 359 (2017).

12. P. R. Shearing, R. S. Bradley, J. Gelb, F. Tariq, P. J. Withers, and N. P. Brandon, "Exploring microstructural changes associated with oxidation in Ni-YSZ SOFC electrodes using high resolution X-ray computed tomography." Solid State Ionics, 216, 69 (2012).

13. P. R. Shearing, R. S. Bradley, J. Gelb, S. N. Lee, A. Atkinson, P. J. Withers, and N. P. Brandon, "Using synchrotron X-ray nano-CT to characterize SOFC electrode microstructures in three-dimensions at operating temperature." Electrochemical and Solid-State Letters, 14(10), B117 (2011).

14. T. M. Heenan, J. B. Robinson, X. Lu, J. J. Bailey, D. J. Brett, and P. R. Shearing, "Analyzing the Mechanical Performance of Solid Oxide Fuel Cells at Interfacial Anode/Electrolyte Regions Using Sub-Micron Resolution 3D X-Ray Computed Tomography." ECS Transactions, 78(1), 2317 (2017).

15. T. M. M. Heenan, J. J. Bailey, X. Lu, J. B. Robinson, F. Iacoviello, D. P. Finegan, D. J. L. Brett, and P. R. Shearing, "Three-Phase Segmentation of Solid Oxide Fuel Cell Anode Materials Using Lab Based X-ray Nano-Computed Tomography." Fuel Cells, 17(1), 75 (2017).

16. T. M. M. Heenan, D. P. Finegan, B. Tjaden, X. Lu, F. Iacoviello, J. Millichamp, D. J. Brett, and P. R. Shearing, "4D nano-tomography of electrochemical energy devices using lab-based X-ray imaging." Nano Energy, 47, 556 (2018).

17. H. Yokokawa, H. Tu, B. Iwanschitz, and A. Mai, "Fundamental mechanisms limiting solid oxide fuel cell durability." Journal of Power Sources, 182(2), 400 (2008).

18. B. Song, E. Ruiz-Trejo, A. Bertei, and N. P. Brandon, "Quantification of the degradation of Ni-YSZ anodes upon redox cycling." Journal of Power Sources, 374, 61 (2018).

19. R. Clague, P. R. Shearing, P. D. Lee, Z. Zhang, D. J. L. Brett, A. J. Marquis, and N. P. Brandon, "Stress analysis of solid oxide fuel cell anode microstructure reconstructed from focused ion beam tomography." Journal of Power Sources, 196(21), 9018 (2011).

20. S. Celik, B. Ibrahimoglu, S. Toros, and M. D. Mat, "Three dimensional stress analysis of solid oxide fuel cell anode micro structure." International Journal of Hydrogen Energy, 39(33), 19119 (2014).

21. J. B. Robinson, L. D. Brown, R. Jervis, O. O. Taiwo, T. M. Heenan, J. Millichamp, T. J. Mason, T. P. Neville, R. Clague, D. S. Eastwood, and C. Reinhard, "Investigating the effect of thermal gradients on stress in solid oxide fuel cell anodes using combined synchrotron radiation and thermal imaging." Journal of Power Sources, 288, 473 (2015).

22. T. M. M. Heenan, J. B. Robinson, X. Lu, B. Tjaden, A. Cervellino, J. J. Bailey, D. J. L. Brett, and P. R. Shearing, "Understanding the thermo-mechanical behavior 
of solid oxide fuel cell anodes using synchrotron X-ray diffraction." Solid State Ionics, 314, 156 (2018).

23. Z. Yan, S. Hara, and N. Shikazono, "Towards a realistic prediction of sintering of solid oxide fuel cell electrodes: From tomography to discrete element and kinetic Monte Carlo simulations." Scripta Materialia, 146, 31 (2018).

24. J. Xu, Y. Higuchi, N. Ozawa, K. Sato, T. Hashida, and M. Kubo, "Parallel Large-Scale Molecular Dynamics Simulation Opens New Perspective to Clarify the Effect of a Porous Structure on the Sintering Process of Ni/YSZ Multiparticles." ACS applied materials \& interfaces, 9(37), 31816 (2017).

25. Y. Zhang and C. Xia, "A durability model for solid oxide fuel cell electrodes in thermal cycle processes." Journal of Power Sources, 195(19), 6611 (2010).

26. B. Sun, R. A. Rudkin, and A. Atkinson, "Effect of Thermal Cycling on Residual Stress and Curvature of Anode-Supported SOFCs." Fuel Cells, 9(6), 805 (2009).

27. J. J. Bailey, T. M. M. Heenan, D. P. Finegan, X. Lu, S. R. Daemi, F. Iacoviello, N. R. Backeberg, O. O. Taiwo, D. J. L. Brett, A. Atkinson, and P. R. Shearing, "Laserpreparation of geometrically optimised samples for X-ray nano-CT." Journal of Microscopy, (2017)

28. Fuel Cell Materials, https://fuelcellmaterials.com/products/equipment/ anode-electrolyte-button-bi-layer/, accessed 10/07/2018.

29. X. Lu, T. M. Heenan, J. J. Bailey, T. Li, K. Li, D. J. Brett, and P. R. Shearing, "Correlation between triple phase boundary and the microstructure of Solid Oxide Fuel Cell anodes: The role of composition, porosity and Ni densification." Journal of Power Sources, 365, 210 (2017).

30. S. J. Cooper, A. Bertei, P. R. Shearing, J. A. Kilner, and N. P. Brandon, "TauFactor: An open-source application for calculating tortuosity factors from tomographic data.' SoftwareX, 5, 203 (2016).
31. C. A. Schneider, W. S. Rasband, and K. W. Eliceiri "NIH Image to Image J: 25 years of image analysis." Nature methods, 9(7), 671 (2012).

32. J. Golbert, C. S. Adjiman, and N. P. Brandon, "Microstructural modeling of solid oxide fuel cell anodes." Industrial \& Engineering Chemistry Research, 47(20), 7693 (2008).

33. K. Sasaki, J. P. Wurth, R. Gschwend, M. Gödickemeier, and L. J. Gauckler, "Microstructure-property relations of solid oxide fuel cell cathodes and current collectors cathodic polarization and ohmic resistance." Journal of the Electrochemical Society, 143(2), 530 (1996).

34. D. Kanno, N. Shikazono, N. Takagi, K. Matsuzaki, and N. Kasagi, "Evaluation of SOFC anode polarization simulation using three-dimensional microstructures reconstructed by FIB tomography." Electrochimica Acta, 56(11), 4015 (2011)

35. X. Lu, T. Li, O. O. Taiwo, J. Bailey, T. Heenan, K. Li, D. J. L. Brett, and P. R. Shearing, "June. Study of the tortuosity factors at multi-scale for a novel-structured SOFC anode." In Journal of Physics: Conference Series, 849(1), 012020 (2017). IOP Publishing.

36. E. Tudisco, E. Andò, R. Cailletaud, and S. A. Hall, "TomoWarp2: a local digital volume correlation code." SoftwareX, 6, 267 (2017).

37. U. P. Muecke, S. Graf, U. Rhyner, and L. J. Gauckler, "Microstructure and electrical conductivity of nanocrystalline nickel-and nickel oxide/gadolinia-doped ceria thin films." Acta Materialia, 56(4), 677 (2008).

38. S. Timoshenko, "Analysis of bi-metal thermostats." JOSA, 11(3), 233 (1925).

39. A. Bertei, E. Ruiz-Trejo, K. Kareh, V. Yufit, X. Wang, F. Tariq, and N. P. Brandon, "The fractal nature of the three-phase boundary: A heuristic approach to the degradation of nanostructured solid oxide fuel cell anodes." Nano Energy, 38, 526 (2017). 